\title{
Difficult but necessary conversations - the case for advance care planning
}

\section{Ian A Scott FRACP, MHA, MEd Director \\ Geoffrey K Mitchell MB BS, FRACGP, PhD, Professor of General Practice and Palliative Care \\ Elizabeth J Reymond MB BS, FRACGP, Clinical Director Metro South Palliativ \\ Care Services $^{3}$ \\ Michael P Daly MB BS, MHA, Director Clinical Governance ${ }^{3}$ \\ 1 Internal Medicin and Clinical \\ Epidemiology, Princess \\ Alexandra Hospital, Brisbane, QLD. \\ 2 University of Queensland Brisbane, QLD. \\ 3 Metro South Hospital and Health Service, Brisbane, QLD. \\ ian.scott@ \\ health.qld.gov.au}

MJA 2013; 199: 662-666 doi:10.5694/mjal3.10158

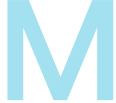
odern medicine saves many people from acute illness who then live longer with chronic illnesses associated with trajectories of declining physical and mental function over months and years, often punctuated by episodes of acute illness or decompensation. Regrettably, considerable suffering as well as dissatisfaction with and overuse of health care result from a mismatch between the needs of chronically ill patients and current practice norms. Advance care planning (ACP) provides a means of ameliorating this mismatch but is yet to be embedded in routine clinical practice or public consciousness.

$\mathrm{ACP}$ is a process of making decisions about future health care for patients in consultation with clinicians, family members and important others. It aims to ensure patients' wishes are respected if they lose decisional capacity. Conceptually, it comprises five sequential phases, from precontemplation to action and maintenance (Appendix 1; online at mja.com.au), ${ }^{1}$ which include completion of a written advance care plan (or advance health directive [AHD], also termed "living will") and the appointment of a surrogate decisionmaker. Unfortunately, in the past, ACP has often been focused on raising completion rates of AHDs, despite there being no guarantee such documents in themselves improve end-of-life $\mathrm{care}^{2}$ or correspond with future care preferences. ${ }^{3}$ A better focus is to encourage widespread use of ACP as a process for iteratively identifying and facilitating what patients consider important for a "good death" (such as managing symptoms, avoiding prolonged dying, achieving a sense of control, relieving burdens placed on the family and strengthening relationships) and for informally communicating their future wishes. ${ }^{4}$

At least $50 \%$ of all deaths in Australia each year are clinically expected because of advanced disease. ${ }^{5}$ In their last year of life, Australians with advanced disease will average eight hospital admissions and incur a 60\%-70\% chance of dying in hospital. 5,6

More than half may be denied adequate opportunity to discuss end-of-life care wishes ${ }^{7}$ or have them fully enacted. ${ }^{8}$ Many patients at the end of life undergo futile (of no benefit at all) or inappropriate (harms outweigh potential benefits) interventions. ${ }^{9}$ Almost a quarter of intensive care beds are occupied by patients receiving potentially inappropriate care, ${ }^{10}$ while up to a quarter of health budgets are spent on inpatient care during the last 18 months of life without any real prospects of extending overall survival or impacting on quality of life. ${ }^{11}$ Most complaints received from bereaved family members about hospital treatment relate to end-of-life care, mainly per-

\section{Summary \\ - Many patients at the end of life receive care that is inappropriate or futile and, if given the opportunity to discuss their care preferences well ahead of death, may well have chosen to forgo such care. \\ - Advance care planning (ACP) is a process of making decisions about future health care for patients in consultation with clinicians, family members and important others, and to safeguard such decisions if patients were to lose decisional capacity. \\ - Although ACP has existed as an idea for decades, acceptance and operationalisation of ACP within routine practice has been slow, despite evidence of its benefits. \\ - The chief barriers have been social and personal taboos about discussing the dying process, avoidance by medical professionals of responsibility for initiating, coordinating and documenting discussions about ACP, absence of robust and standardised procedures for recording and retrieving ACP documents across multiple care settings, and legal and ethical concerns about the validity of such documents. \\ - For ACP to become part of mainstream patient-centred care, accountable clinicians working in primary care, hospitals and nursing homes must effectively educate colleagues and patients about the purpose and mechanics of ACP, mandate ACP for all eligible patients, document ACP in accessible formats that enable patient wishes to accurately guide clinical management, devise methods for reviewing ACP decisions when clinically appropriate, and evaluate congruence between expressed patient wishes and actual care received. \\ - Public awareness campaigns coupled with implementation of ACP programs sponsored by collaborations between hospital and health services, Medicare locals and residential care facilities will be needed in making system-wide ACP a reality.}

ceived failures of communication and preparedness for death. ${ }^{12}$ In one study, doctors spent a median time of only 1 minute on do-not-resuscitate discussions with patients after admission. ${ }^{13}$

Randomised trials of ACP are few and report mixed results. The sentinel trial, SUPPORT (Study to Understand Prognoses and Preferences for Outcomes and Risks of Treatments), which used nurse facilitators over 2 years to undertake discussions with seriously ill hospitalised patients and families and document their preferences, showed no improvement in patient control over their treatment. ${ }^{14}$ However, a more recent trial of ACP showed improved patient and family satisfaction and alleviation of anxiety in relatives of hospitalised patients. ${ }^{15}$ Observational studies have shown similar findings. ${ }^{16}$ Other randomised trials ${ }^{17}$ and before-and-after studies ${ }^{18}$ involving 


\section{Tips for successful advance care planning conversations*}

- The individual needs to be ready for the conversation and mentally capable of participating - conversation cannot be forced, but at the same time clinicians, in most instances, need to take the lead in initiating such conversations.

- Capacity to engage in conversation must be maximised by treating any transient condition affecting communication and optimising sensory function (eg, by ensuring the patient's hearing aid is being worn).

- Conversations need to take place on more than one occasion (over days, weeks, even months) and should not be completed on a single visit in most circumstances.

Conversations take time and effort and cannot be completed as a simple checklist exercise.

- Conversations should take place in comfortable, unhurried surroundings; time is a key factor.

- Conversations should be devoid of medical jargon, language should be positive, and trust must be built using empathic listening skills.

- A step-by-step approach to identifying and resolving issues should be used (see Box 2), coupled with "time-out" periods where doctors withdraw from the encounter for some minutes to allow patient and family to discuss between them the care options that have been presented.
- Individuals should be given realistic information on prognosis and treatment options with emphasis on how their illness is expected to impact on their daily function.

- Conversations should avoid focusing initially on medical interventions (eg, cardiopulmonary resuscitation, intubation) but rather determine values, goals, and preferences (eg, prolonging life and preserving mentation versus minimising suffering and avoiding undignified states or an unacceptable functional status).

- Look out for cues suggesting individuals are becoming uncomfortable talking about certain issues or may wish to end the conversation.

- Encourage patients to identify a surrogate decisionmaker and to discuss their wishes with that individual; if desired, offer to facilitate a conversation between patients and their surrogate or other family members; identify whether patients have specific desires for how information is shared among family members.

- Summarise and check patient's and, if they are present, surrogates' understanding of what has been discussed at end of sessions.

- Encourage patient and surrogates to have conversations documented but reassure them these documents are not necessarily final or binding.

- Plan for a review as clinical circumstances change.

*Adapted from Advance care planning. Concise Guidance to Good Practice series, No. 12. London: Royal College of Physicians, 2009.34

nursing home residents have shown $40 \%$ to $80 \%$ reductions in rates of hospitalisation and up to threefold increases in palliative care referrals resulting from advance care directives. Experience with ACP in the aged care sector in Victoria has shown that less than 3\% of residents in aged care facilities approached about ACP declined it, and $90 \%$ of those who completed ACP died in the facility while receiving palliation rather than in hospital, compared with only $50 \%$ of those who had not completed ACP. ${ }^{19}$ Use of ACP invokes earlier initiation of more appropriate palliative care, which improves patient symptoms and mood, reduces undesired use of invasive interventions and life-sustaining treatments, lowers the likelihood of inhospital death, prolongs life of higher quality and decreases costs. ${ }^{20-22}$

\section{Challenges in advance care planning}

Regardless of potential benefits, ACP uptake in Australia has been slow, despite widespread professional and public endorsement coupled with supporting legislation in every state and territory. However, many hospitals and nursing homes are now implementing ACP programs, most along the lines of the Respecting Patient Choices program initiated at Austin Hospital in 2002. ${ }^{23}$ Factors inhibiting universal adoption of ACP are several:

- Reluctance to acknowledge impending mortality: Reflecting societal norms, most individuals, including clinicians, find it difficult to think and talk about dying.

- Perceived irrelevance: Many patients may perceive themselves as being "too healthy", hope (often unrealistically) for medical technology to prolong healthy life, regard future events as a matter of fate, or consider their wishes are already known to doctors and family. ${ }^{24}$

- Issues of timing: Intuitive prognostications of clinicians can be inaccurate, with formal prediction tools offering limited assistance. ${ }^{25}$ Consequently, "curative intent" remains the focus, with initiation of ACP often occurring too late, leading to rushed care decisions and suboptimal outcomes.

- Diffusion of responsibility: The role of initiating and coordinating ACP, which must encompass all patient needs — clinical, emotional and spiritual — must be accepted by someone. Patients often wait for doctors to broach the subject, while clinicians wait for patients or family members to do so. General practitioners wait for a signal from specialists that may never come if multiple specialists are involved, with no one taking charge overall. ${ }^{26}$

- Limited clinician time, skill and remuneration: The pressure of clinical work, a focus on managing acute medical problems and the absence of suitable training and remuneration discourages clinicians from dedicating time to ACP.

- Limitations of surrogate decisionmakers: The views of proxies and patients are often discordant, ${ }^{27}$ or there may be conflicts between family members. Surrogate decisionmakers may not want to assume sole responsibility, and subsequent guilt, for terminating life-sustaining measures.

- Ambiguous, inconstant or poorly recorded wishes: Patient preferences can change over time, are often based on wrong or insufficient information, or are documented in vague, incomplete terms on forms not easily retrieved when needed. Because of this lack of clarity at the time of decision making, doctors and surrogates may disregard or feel incapable of enacting expressed wishes, especially if legal or ethical concerns persist around patients' decisional capacity at the time ACP documents were written or altered.

- Differing perceptions of ACP: Many people feel intimidated by what they perceive as legally binding and irrevocable AHDs which arise from ACP. Others equate ACP with palliative care, which they assume indicates imminent death due to a rapidly terminal illness. Finally, some link ACP with euthanasia or assisted suicide, which has seen doctors in the United States who discuss ACP with patients being caricatured as "death panels". ${ }^{28}$ 


\section{Concerns and safeguards in advance care planning (ACP)}

\section{Concerns}

Lack of understanding and recall

- Poor patient understanding following ACP discussions

- Low concordance between recollections of patient and physicians or proxies

- Lack of recall of care decisions into the future

- Patient uncertainty about care wishes, especially among patients from non-English speaking backgrounds or with low levels of literacy

\section{Coercion}

- Undue influence of clinicians in care decisions who may rate patient quality of life considerably lower than patients themselves

- Coercion of patients and proxies to agree to limitations of life-sustaining therapy

Inflexibility

- Inflexibility of "locked-in" ACP documents that are not responsive to changes in clinical circumstances and/or patient and proxy preferences
Safeguards

- Provide comprehensible information sufficient to allow patients to feel comfortable with their level of understanding

- Before terminating conversations, reiterate decisions to ensure patients, clinicians and proxies are all "on the same page"

- Provide copies of summaries of conversations (including videorecordings of the sessions) on request at their conclusion

- Involve family and interpreters in ACP conversations and documentation. Conduct conversations at the appropriate level of literacy and involve health professionals of similar ethnic background

- Involve more than one health professional in ACP conversations and include individuals who have not been directly involved in the patient's care up to that point in time

- Emphasise and reiterate the goals of ACP that respect patient autonomy and wishes within the bounds of care that is not deemed to be futile

- Use a range of ACP procedures - one size does not fit all - with initial emphasis on eliciting values and preferences rather than concrete treatment decisions

- Apply any ACP document or advance health directive only to a decisionally incompetent patient or a patient who is unable to communicate. Competent and conversant patients can always speak for themselves

- Undertake ACP conversations in non-emergent situations when patients are clinically stable and not mentally impaired by reversible illness

- Update ACP documents regularly and whenever circumstances change significantly

\section{Elements of successful advance care planning}

Given these challenges, no single strategy will achieve the transition of patients and their proxies from pre-contemplation to action in $\mathrm{ACP} .^{29}$ The most effective and systematic, yet personalised, approach comprises structured, iterative conversations about values and preferences for end-of-life care led by trained, trusted and paid facilitators (who may include nurses and social workers as well as doctors). Such conversations occur over several visits, actively involve properly informed surrogates, and are supported by oral, written and videorecorded information. In these interactions, an advance care plan or a medical enduring power of attorney may serve as more versatile media for ACP than a static AHD. ${ }^{30}$

\section{Timing of the conversation}

Contemplation of ACP by patients and their clinicians often starts with recent serious illness or major surgery, worsening symptoms and functional decline, or experience with ACP involving significant others. ${ }^{31}$ Lay texts ${ }^{32}$ and public engagement campaigns such as the Conversation Project in the US (www.theconversationproject.org) and Dying Matters Coalition in the United Kingdom (www.dyingmatters.org) encourage people to have "kitchen table" end-of-life care discussions with family members and then with their doctors. Furthering these conversations requires proactive intervention by clinicians who are highly knowledgeable of the clinical profile of individual patients and the burdens of disease-specific treatment options, able to identify triggers for opportunistic discussions about ACP, cognisant of both physical and non-physical domains of health, and trained in communication and shared decision-making skills.
While the timing of ACP must be sensitive to patients' readiness to enter into such conversations, a pragmatic three-step guide for clinicians ${ }^{33}$ is to consider ACP if: - "No" is the answer to this question: "In light of all you know about this patient, would you be surprised if he/she was to die within the next 6 to 12 months?";

- the patient's general health is poor (eg, limitations in self-care, multiple hospitalisations); and

- disease-specific indicators portend a poor prognosis (eg, advanced organ failure, dementia, disabling neurological conditions, progressive malignancies).

Specific triggers for ACP discussion might include: new diagnoses of life-limiting conditions; severe, irreversible deterioration in the patient's health status; loss of response to, or complications from, disease-specific treatments; unrealistic expectations or requests for care by the patient or their family; or an expressed desire of the patient or their family to discuss ACP.

\section{Initiating and holding the conversation}

Initial reactions of patients and family to ACP can be negative, but responses usually improve as issues are clarified and resolved. Patient comfort in discussing endof-life care is facilitated by a stepped approach and use of facilitative language (Appendix 2; online at mja.com.au). The first step is a values discussion aimed at defining values, goals and preferences for care in general (advance statement of preferences or wishes) and only later moving to more binding decisions about specific forms of care under specific circumstances (advance decisions). A key task is ascertaining which patient wants what information at this particular time, while respecting preferences for silence. Identifying a surrogate decisionmaker and involv- 
3 System-wide strategies for embedding advance care planning (ACP) into routine care

\section{Primary care settings}

Use computer reminders to initiate ACP discussions in eligible patients at upcoming doctor appointments.

Mail introductory ACP material to eligible patients.

Dedicate time for ACP within annual comprehensive medical assessments and extended primary care consultations.

Train practice nurses or social workers to act as case managers in ACP for patients following initial discussions with doctors.

\section{Hospitals}

Initiate conversations about ACP when admitting frequently hospitalised patients, formulating acute resuscitation plans or care pathways for chronically ill patients and caring for patients transferred from or to residential care facilities.

Place clinicians skilled in ACP in all units with sizeable numbers of chronically ill patients (general and geriatric medicine, oncology, cardiac and respiratory), tasking them with identifying and counselling suitable patients and imparting ACP skills to other staff. Document the status of ACP discussions in discharge summaries. Discharge co-ordinators ensure ACP information is communicated to all external clinicians.

Foster staff awareness of ACP using screensaver messages on workstation computers and posters and brochures on noticeboards.

\section{Residential care facilities}

Routinely initiate ACP conversations between senior nurses and patients and their proxies following admission, after any major change in clinical status and at yearly intervals, or more frequently depending on change in clinical status.

Make easy-to-read ACP information available to all new residents, and display promotional material for staff and facility visitors.

Require facility-affiliated general practitioners and geriatricians, working with senior nurses, to undertake ACP training and information sessions and implement and audit ACP processes according to best practice.

\section{Accessibility, standardisation and auditing of} ACP documents

Require hospital and health services, Medicare locals and residential care facilities to generate and use area-wide ACP document templates that are standardised, simple, patient-friendly and readily downloadable at the point of care. File copies of completed advance care plans and/or AHDs in a consistent manner, flag them on all patient records (including patient-controlled electronic health records) and ensure they are able to be rapidly retrieved, preferably via a centralised electronic registry.

Store ACP documents with electronic medical records to enable quick communication regarding changes in plans to all parties involved through shared portals.

Provide patient-held wallet cards or alert bracelets to flag the existence of ACP documents for the benefit of ambulance services and emergency physicians at times of crisis.

Regularly audit ACP processes and document the level of congruence between expressed patient wishes and the care actually received.

\section{Professional training}

Ensure all clinicians, especially doctors, case managers and social workers, undergo training in ACP and appropriate communication skills using simulation techniques, role-play, scenario analyses and computer-based decision aids.

Include measures of competency in ACP in professional credentialling processes.

\section{Public awareness}

Display brochures and texts that introduce ACP (such as Planning your future care, available at www.endoflifecareforadults.nhs.uk) in clinics and interview rooms and on noticeboards.

Recruit health professionals to sponsor and participate in public engagement campaigns that serve to both educate and prompt patients in discussing ACP.

Create a national clearinghouse for ACP information, document templates and related laws that cover all Australian state and territory jurisdictions.

Highlight user-friendly websites and resources for consumers and professionals in lay and professional news media.

Educate the public in the skills and benefits of shared decision making. ing them in discussions around foreseeable events should also occur at an early stage. Patients and surrogates should be reassured that responsibility for terminating life-sustaining measures will be shared between clinicians (as technical medical experts) and themselves (as experts on patients' values and preferences).

Further tips for ensuring successful ACP conversations are listed in Box $1,{ }^{34}$ and useful resources, including ACP document templates, are available in various texts ${ }^{35}$ and from several websites: Advance Care Planning Australia (http://advancecareplanning.org.au); National Health Service Improving Quality (http://www.endoflifecare.nhs.uk/care-pathway/step-2-assessment,-care-planning-and-review/preferred-priorities-for-care.aspx); and the Conversation Project (www.theconversationproject.org). Legitimate concerns about ACP can be mitigated by instituting appropriate safeguards (Box 2).

\section{Strategies for embedding advance care planning} into routine care

In embedding ACP into routine practice, all health care organisations (general practices, hospitals, residential care facilities) need to become "conversation ready"; that is, committed to systematically eliciting, documenting and enacting patients' care preferences. ${ }^{36}$ System-wide processes (Box 3) are needed that will consistently:

- invite all eligible patients to consider ACP for future care relevant to their stage of illness;

- provide competent assistance by trained and accountable personnel; and

- ensure written plans (however documented) are

$>$ accurate, relevant and understandable to all stakeholders

$>$ stored, transferred and retrieved wherever the patient is being treated

$>$ updated and rendered more specific as illnesses progress

$>$ sighted and honoured at the right time.

Given their longstanding, trusted relationships with patients, GPs are probably best placed for timely ACP, but they need to be supported in this task by medical specialists, senior nurses and allied health professionals. Legal clarification is required regarding the need for advance care plans or AHDs to comply with specific forms, their transferability between jurisdictions, their scope in covering all future treatment decisions, and the enforceability of oral plans or directives. In all Australian jurisdictions, competent patients or surrogate decisionmakers cannot demand treatment that clinicians believe to be futile, including enteral or intravenous nutrition and hydration. There are no reports of Australian or UK courts overturning a carefully considered decision to withhold treatment doctors deemed to be futile. ${ }^{37}$

The goals of ACP are indisputable and its benefits are becoming evident. If $\mathrm{ACP}$ is to become a mainstream clinical activity, health care services and professionals must effectively educate themselves and their patients about its purpose. They must take practical steps to implement auditable ACP systems in routine practice, document ACP in accessible formats that enables patient wishes to accu- 
rately guide clinical management, review ACP decisions when clinically required, and evaluate the effects of ACP on clinical outcomes and the fulfilment of patients' wishes.

Acknowledgements: lan Scott and Geoffrey Mitchell are chief investigators of the National Health and Medical Research Council Centre for Research Excellence in Quality and Safety in Integrated Primary/Secondary Care, which sponsored their work (NHMRC grant 1001157).

Competing interests: No relevant disclosures.

Provenance: Not commissioned; externally peer reviewed.

1 Fried TR, Redding CA, Robbins ML, et al. Stages of change for the component behaviours of advance care planning. J Am Geriatr Soc 2010; 58: 2329-2336.

2 Prendergast TJ. Advance care planning: pitfalls, progress, promise. Crit Care Med 2001; 29 (2 Suppl): N34-N39.

3 Winter L, Parks SM, Diamond JJ. Ask a different question, get a different answer: why living wills are poor guides to care preferences at the end of life. JPalliat Med 2010; 13:567-572.

4 Steinhauser KE, Clipp EC, McNeilly M, et al. In search of a good death: observations of patients, families, and providers. Ann Intern Med 2000; 132: 825-832.

5 Rosenwax LK, McNamara BA. Who receives specialist palliative care in Western Australia - and who misses out. Palliat Med 2006; 20: 439-445.

6 Rosenwax LK, McNamara BA, Murray K, et al. Hospital and emergency department use in the last year of life: a baseline for future modifications to end-of-life care. Med J Aust 2011; 194: 570-573.

7 Covinsky KE, Fuller JD, Yaffe K, et al. Communication and decision-making in seriously ill patients: findings of the SUPPORT project: the Study to Understand Prognoses and Preferences for Outcomes and Risks of Treatments. J Am Geriatr Soc 2000; 48 (5 Suppl): S187-S193.

8 Teno JM, Licks S, Lynn J, et al. Do advance directives provide instructions that direct care? J Am Geriatr Soc 1997; 45: 508-512.

9 Walling AM, Asch SM, Lorenz KA, et al. The quality of care provided to hospitalised patients at the end of life. Arch Intern Med 2010; 170: 1057-1063.

10 Piers RD, Azoulay E, Ricou B, et al; APPROPRICUS Study Group of the Ethics Section of the ESICM. Perceptions of appropriateness of care among European and Israeli intensive care unit nurses and physicians. JAMA 2011; 306: 26942703.

11 Van Weel C, Michels J. Dying, not old age, to blame for costs of health care. Lancet 1997; 350: 1159-1160.

12 Healthcare Commission. Spotlight on complaints: a report on second-stage complaints about the NHS in England. 2009. http://www.nottingham.ac.uk/ leighs/documents/2009healthcommissionspotlightoncomplaints.pdf (accessed Oct 2013).

13 Anderson WG, Chase R, Pantilat SZ, et al. Code status discussions between attending hospitalist physicians and medical patients at hospital admission. J Gen Intern Med 2011; 26: 359-366.

14 The SUPPORT Principal Investigators. A controlled trial to improve care for seriously ill hospitalized patients. The Study to Understand Prognoses and Preferences for Outcomes and Risks of Treatments (SUPPORT). JAMA 1995; 274: 1591-1598.

15 Detering KM, Hancock AD, Reade MC, Silvester W. The impact of advance care planning on end of life care in elderly patients: randomised controlled trial. BMJ 2010; 340: c1345.

16 Wright AA, Zhang B, Ray A, et al. Associations between end-of-life discussions, patient mental health, medical care near death, and caregiver bereavement adjustment. JAMA 2008; 300: 1665-1673.
17 Molloy DW, Guyatt GH, Russo R, et al. Systematic implementation of an advance directive program in nursing homes: a randomized controlled trial. JAMA 2000; 283: 1437-1444.

18 Levy C, Morris M, Kramer A. Improving end-of-life outcomes in nursing homes by targeting residents at high-risk of mortality for palliative care: program description and evaluation. J Palliat Med 2008; 11: 217-225.

19 Australian Government Productivity Commission draft report on caring for older Australians. Submission by the Respecting Patient Choices "Making Health Choices" Steering Committee. 2007. http://www.pc.gov.au/_data/ assets/pdf_file/0003/108876/subdr0803.pdf (accessed Mar 2013).

20 Temel JS, Greer JA, Muzikansky A, et al. Early palliative care for patients with metastatic non-small-cell lung cancer. N Engl J Med 2010; 363: 733-742.

21 Bakitas M, Lyons KD, Hegel MT, et al. Effects of a palliative care intervention on clinical outcomes in patients with advanced cancer: the Project ENABLE II randomized controlled trial. JAMA 2009; 302: 741-749.

22 Abel J, Pring A, Rich A, et al. The impact of advance care planning of place of death, a hospice retrospective cohort study. BMJ Support Palliat Care 2013; 3: 168-173.

23 Lee MJ, Heland M, Romios P, et al. Respecting patient choices: advance care planning to improve patient care at Austin Health. Health Issues 2003; 77: 23 26. http://www.healthissuescentre.org.au/documents/items/2008/05/ 206717-upload-00001.pdf (accessed Jun 2013).

24 Schickedanz AD, Schillinger D, Landefeld CS, et al. A clinical framework for improving the advance care planning process: start with patients' selfidentified barriers. J Am Geriatr Soc 2009; 57: 31-39.

25 Coventry PA, Grande GE, Richards DA, Todd CJ. Prediction of appropriate timing of palliative care for older adults with non-malignant life-threatening disease: a systematic review. Age Ageing 2005; 34: 218-227.

26 Stavert RR, Lott JP. The bystander effect in medical care. NEngl J Med 2013; 368: 8-9.

27 Shalowitz DI, Garrett-Mayer E, Wendler D. The accuracy of surrogate decision makers: a systematic review. Arch Intern Med 2006; 166: 493-497.

28 Tinetti ME. The retreat from advanced care planning. JAMA 2012; 307: 915-916.

29 Tamayo-Velázquez MI, Simón-Lorda P, Villegas-Portero R, et al. Interventions to promote the use of advance directives: an overview of systematic reviews. Patient Educ Couns 2010; 80: 10-20.

30 Messinger-Rapport BJ, Baum EE, Smith ML. Advance care planning: beyond the living will. Cleve Clin J Med 2009; 76: 276-285.

31 Alano GJ, Pekmezaris R, Tai JY, et al. Factors influencing older adults to complete advance directives. Palliat Support Care 2010; 8: 267-275.

32 Winch S. Best death possible: a guide to dying in Australia. Brisbane: Palmer Higgs Books, 2013.

33 Boyd K, Murray SA. Recognising and managing key transitions in end of life care. BMJ 2010; 341: c4863.

34 Royal College of Physicians, National Council for Palliative Care, British Society of Rehabilitation Medicine, British Geriatrics Society, Alzheimer's Society, Royal College of Nursing, Royal College of Psychiatrists, Help the Aged, Royal College of General Practitioners. Advance care planning. Concise Guidance to Good Practice series, No. 12. London: RCP, 2009. http://www.rcplondon.ac.uk/sites/ default/files/documents/acp_web_final_21.01.09.pdf (accessed Mar 2013).

35 Thomas K, Lobo B, editors. Advance care planning in end of life care. Oxford: Oxford University Press, 2011.

36 Lynn J, Nolan K, Kabcenell A, et al; End-of-Life Care Consensus Panel. Reforming care for persons near the end of life: the promise of quality improvement. Ann Intern Med 2002; 137: 117-122.

37 Thiagarajan M, Savulescu J, Skene L. Deciding about life-support: a perspective on the ethical and legal framework in the United Kingdom and Australia. J Law Med 2007; 14:583-596. 